\title{
BEHAVIOUR AND DESIGN OF STEEL-CONCRETE-STEEL-SANDWICH CONSTRUCTION
}

\author{
N. Foundoukos ${ }^{1, *}$, M. Xie ${ }^{2}$, and J.C. Chapman ${ }^{3}$ \\ ${ }^{1}$ Imperial College of Science Technology and Medicine, London SW7 2AZ, UK, , fax 00442075945934 \\ ${ }_{2}^{2}$ KW Ltd, Fetcham Park House, Lower Road, Fetcham, Surrey KT22 9HD, UK, mxie@kwltd.com \\ ${ }^{3}$ Imperial College of Science Technology and Medicine, London SW7 2AZ, UK, jcrbchapman@globalnet.co.uk \\ *(Corresponding author: E-mail: nf2@ic.ac.uk)
}

\begin{abstract}
Static and fatigue tests have been conducted on Bi-Steel steel-concrete-steel sandwich beams. A truss mi with tapering web compression members is proposed for calculating the forces within the beams. The model $\mathrm{g}$ conservative predictions of the failure loads and modes of the beams. A deflection equation has been developed taking account the slip between steel plates and concrete, giving good agreement with measured values. A fatigue life calcula method has been proposed which takes into account interaction of the applied forces at bar-plate connections and $g$ conservative predictions of fatigue life.
\end{abstract}

Keywords: Sandwich construction, bi-steel, static tests, beams, strength, deflection, fatigue

\section{INTRODUCTION}

Bi-Steel is an innovative form of steel-concrete-steel sandwich construction invented by Bowerman [1], in which the two steel plates are inter-connected by a series of transverse bar connectors simultaneously friction welded at both ends (Figure 1). A design guide was published by CORUS [2], based on testing and on existing design codes for steel and reinforced concrete.

The prime function of shear connectors in conventional composite beams is to resist longitudinal shear, but they also prevent uplift of the slab from the beam. In Bi-Steel members the bar connectors are connected to the plates at both ends, and their function is to resist both longitudinal and transverse shear, in addition to preventing plate buckling. The connectors are subjected to shear, tension or compression, and bending. The purpose of the research project at Imperial College was to validate or improve the existing design recommendations. Static and fatigue tests on components under single and combined loads were performed $[3,4]$ to give the load capacity and fatigue life of the connection. The results of the static and fatigue tests on Bi-Steel beams were used in design formulation.

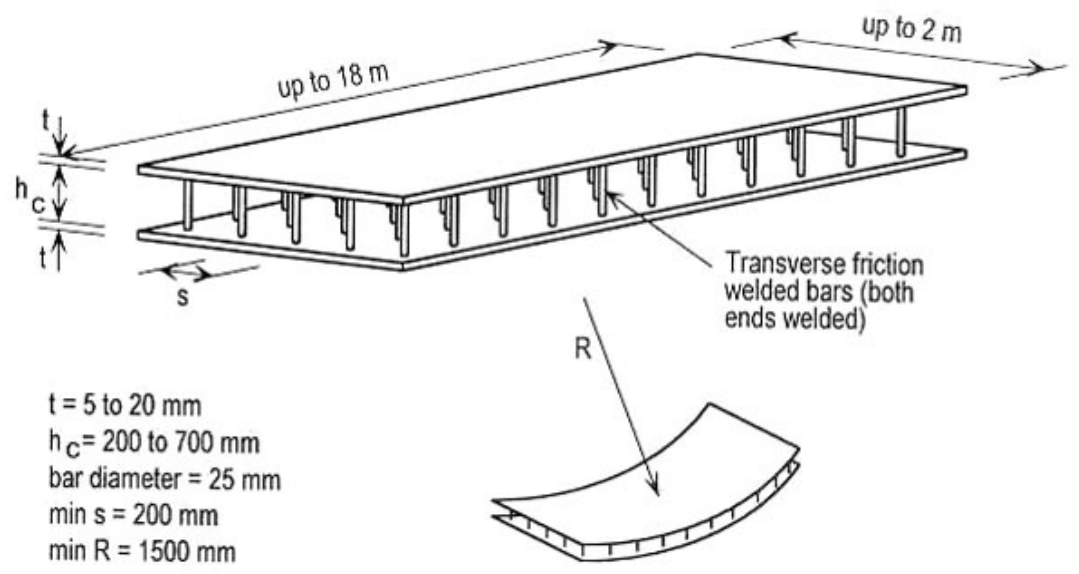

Figure 1. Bi-Steel Sandwich Construction 


\section{ANALYTICAL MODELS}

\subsection{Equivalent Steel Beam}

The equivalent steel beam approach (Figure $2 b$ ) is recommended in the current design guide. The assumptions are that the steel and concrete are elastic, but the concrete has no tensile strength, and that the plates are continuously connected to the concrete. The width of concrete is assumed to be reduced in proportion to the modular ratio $\mathrm{m}$ between steel and concrete $\left(\mathrm{m}=\mathrm{E} / \mathrm{E}_{\mathrm{c}}\right)$. The bar connector shear forces can then be estimated from the change in plate force over a length equal to the bar spacing. The model does not provide a means for calculating bar tension, or for resisting transverse shear. The assumption of continuous connection leads to an incorrect estimate of force in the compression plate. The model does not provide for a rigorous method for calculating the slip deflection which was found to be the largest deflection component.

\section{$2.2 \quad$ Truss Model}

A truss model with tapering web compression members is proposed for analysis of Bi-Steel beam member forces (Figure 2a, c). The area of concrete in longitudinal compression can be determined from the equivalent steel section. The truss model consists of pin jointed line elements in which the axial stress is uniform across a section. To achieve this the uniform web thickness over which, according to the equivalent beam model, the stress varies, is replaced by a tapering web across which the stress is constant, with the requirement that the total compressive forces are equal to that in the equivalent beam model, and that the depth of the compression zones $y_{m}$ are also equal. The depth $\mathrm{h}$ of the truss is equal to the distance from the mid-thickness of the bottom plate to the centroid of the compression area (Figure 2c); h is given by Eqs. (1), (2), (3).

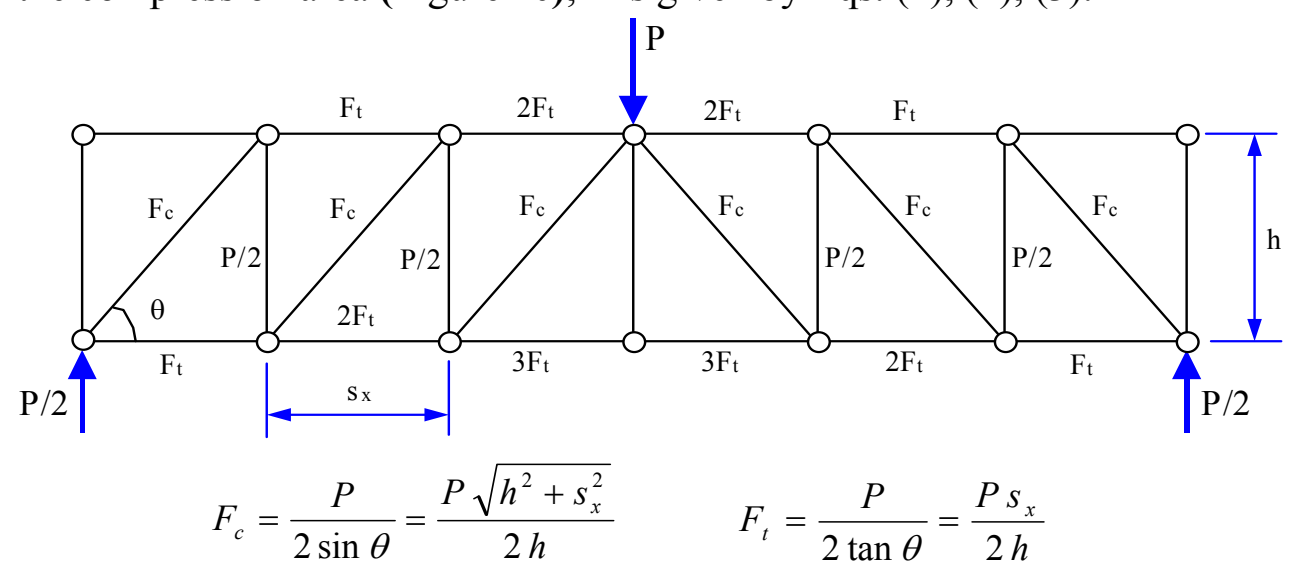

(a) Truss model for a Bi-Steel beam

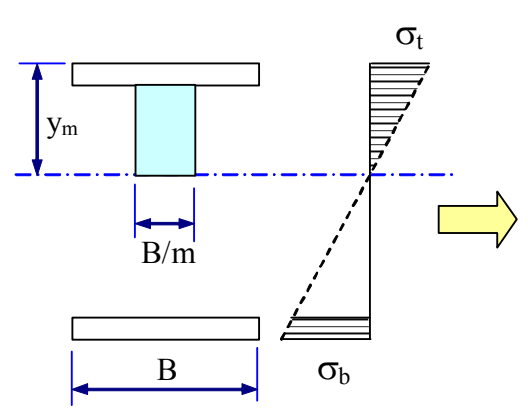

(b) Equivalent steel section

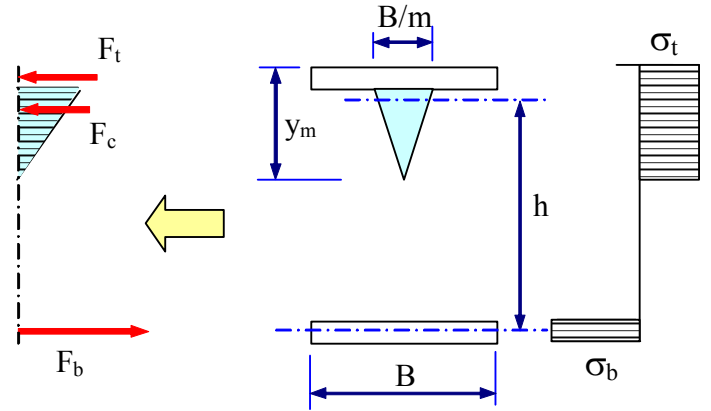

(c) Cross section of truss members

Figure 2. Calculation of the Depth of Truss, $h$ 
$h=\frac{m t_{t}\left(2 h_{c}+t_{t}+t_{b}\right)+\left(y_{m}-t_{t}\right)\left[h_{c}-\left(y_{m}-t_{t}\right) / 3+t_{b} / 2\right]}{2 m t_{t}+y_{m}-t_{t}}$

where $\mathrm{y}_{\mathrm{m}}$ is given by: $y_{m}=-\alpha+\sqrt{\alpha^{2}-2 \beta}$

with: $\alpha=m\left(t_{t}+t_{b}\right)-t_{t} \quad \beta=-\left(h_{c}+t_{t}+t_{b}\right) m t_{b}+\left(m t_{b}^{2}-m t_{t}^{2}+t_{t}^{2}\right) / 2$

An inherent characteristic of this model is that the plates are connected to the concrete only at the nodal points. That is, there is no bond between steel and concrete, as in reality, which gives a correct estimate of the plate forces.

\section{EXPERIMENTATION}

Eighteen beams were tested statically. The beams were designed to cover a range of geometrical properties, and to enable different failure modes to be observed. Details of the beams are given in Table 1 and illustrated in Figure 3.

Table 1. Geometrical Dimensions of the Test Beams and Material Properties

\begin{tabular}{ccccccccccc}
\hline $\begin{array}{c}\text { Beam } \\
\text { No. }\end{array}$ & $\begin{array}{c}\mathrm{t}_{\mathrm{b}} \\
(\mathrm{mm})\end{array}$ & $\begin{array}{c}\mathrm{t}_{\mathrm{t}} \\
(\mathrm{mm})\end{array}$ & $\begin{array}{c}\mathrm{h}_{\mathrm{c}} \\
(\mathrm{mm})\end{array}$ & $\begin{array}{c}\mathrm{s}_{\mathrm{x}} \\
(\mathrm{mm})\end{array}$ & $\mathrm{L}(\mathrm{mm})$ & $\begin{array}{c}\mathrm{f}_{\mathrm{yP}}{ }^{*} \\
\left(\mathrm{~N} / \mathrm{mm}^{2}\right)\end{array}$ & $\begin{array}{c}\mathrm{f}_{\mathrm{uP}}{ }^{*} \\
\left(\mathrm{~N} / \mathrm{mm}^{2}\right)\end{array}$ & $\begin{array}{c}\mathrm{f}_{\mathrm{yB}} \\
\left(\mathrm{N} / \mathrm{mm}^{2}\right)\end{array}$ & $\begin{array}{c}\mathrm{f}_{\mathrm{uB}} \\
\left(\mathrm{N} / \mathrm{mm}^{2}\right)\end{array}$ & $\begin{array}{c}\mathrm{f}_{\mathrm{cu}} \\
\left(\mathrm{N} / \mathrm{mm}^{2}\right)\end{array}$ \\
\hline BS1 & 6.23 & 6.23 & 400 & 200 & 1200 & 384 & 507 & 541 & 566 & 58 \\
BS2 & 7.91 & 7.91 & 400 & 200 & 1200 & 381 & 518 & 541 & 566 & 58 \\
BS3 & 11.96 & 11.96 & 400 & 200 & 1200 & 419 & 563 & 541 & 566 & 58 \\
BS4 & 6.13 & 11.95 & 200 & 200 & 1200 & 384 & 507 & 541 & 566 & 58 \\
BS5 & 7.91 & 11.93 & 200 & 200 & 1200 & 381 & 518 & 541 & 566 & 58 \\
BS6 & 11.83 & 11.83 & 200 & 200 & 1200 & 419 & 563 & 541 & 566 & 58 \\
BS7 & 6.20 & 11.93 & 200 & 300 & 1800 & 384 & 507 & 541 & 566 & 58 \\
BS8 & 7.98 & 11.82 & 200 & 300 & 1800 & 381 & 518 & 541 & 566 & 58 \\
BS9 & 11.90 & 11.90 & 200 & 300 & 1800 & 419 & 563 & 541 & 566 & 58 \\
BS10 & 6.10 & 11.95 & 200 & 400 & 2400 & 384 & 507 & 541 & 566 & 58 \\
BS11 & 7.98 & 11.88 & 200 & 400 & 2400 & 381 & 518 & 541 & 566 & 58 \\
BS12 & 11.92 & 11.92 & 200 & 400 & 2400 & 419 & 563 & 541 & 566 & 58 \\
BS13 & 10.31 & 10.21 & 300 & 200 & 1600 & 430 & 548 & 553 & 586 & 40 \\
BS14 & 11.88 & 11.83 & 300 & 200 & 1600 & 431 & 571 & 553 & 586 & 40 \\
BS15 & 10.02 & 10.27 & 300 & 300 & 1800 & 430 & 548 & 553 & 586 & 40 \\
BS16 & 11.76 & 11.83 & 300 & 300 & 1800 & 431 & 571 & 553 & 586 & 40 \\
BS17 & 10.18 & 10.21 & 300 & 300 & 2400 & 430 & 548 & 553 & 586 & 40 \\
BS18 & 11.93 & 11.89 & 300 & 300 & 2400 & 431 & 571 & 553 & 586 & 40 \\
\hline
\end{tabular}

* Note: The yield stress and the ultimate strength of the tension steel plates are listed. 


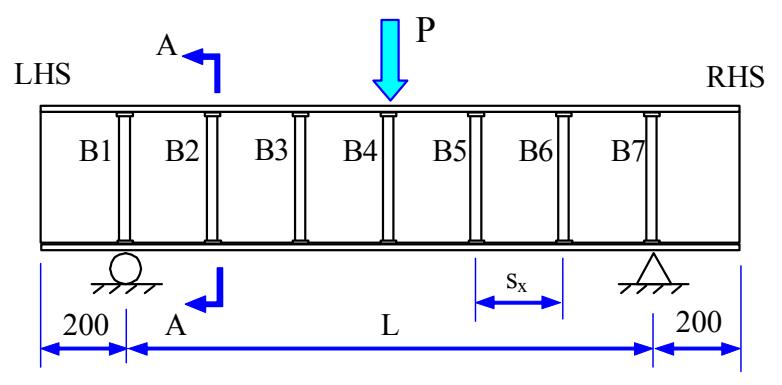

$\mathbf{L} / \mathbf{s}_{\mathbf{x}}=\mathbf{6}$

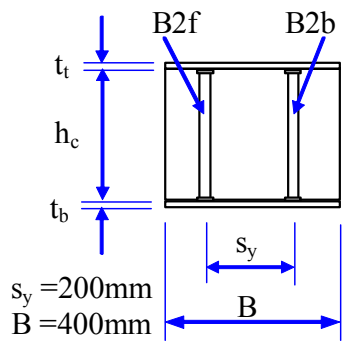

$\underline{\mathbf{A}-\mathbf{A}}$

Figure 3. Details of the Test Beams. $B=400 \mathrm{~mm}, s_{y}=200 m m, s_{x}, h_{c}, t_{t}$ and $t_{b}$ Vary

The beams were supported on a fixed cylindrical bar at one end and a roller at the other end. Equal forces were applied by two 100ton (static) jacks at midspan. Strain gauges and displacement transducers were used to record strains, slip and deflections at key positions in the beams.

\section{TEST RESULTS AND COMPARISONS}

\subsection{Failure Loads and Modes}

The measured failure loads and failure modes for the 18 beams are summarised in Table 2. Figure 4 illustrates the four elementary modes of failure observed in the test beams.

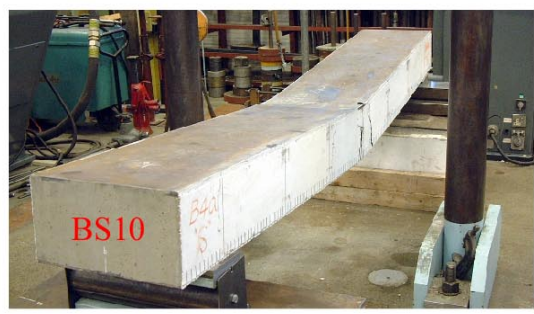

Tension plate failure

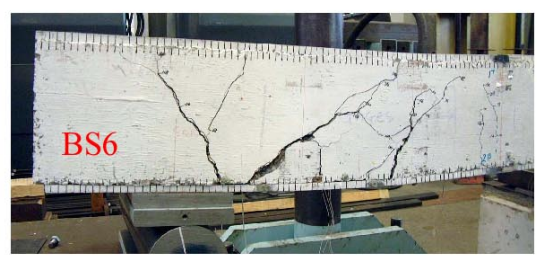

Concrete shear failure

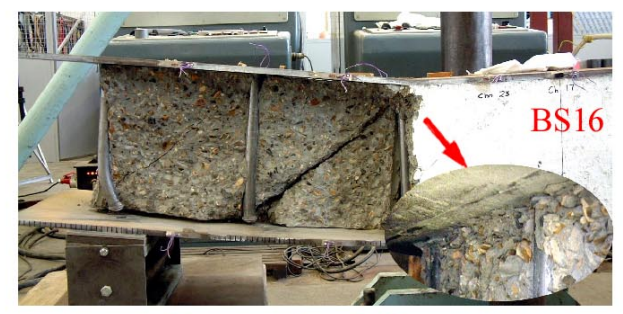

Bar tension failure

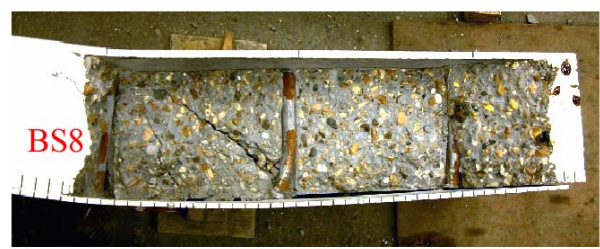

Bar shear failure

Figure 4. Typical Beam Static Failure Modes

Failure loads were calculated using the truss model. The failure load for each possible failure mode was determined in terms of the ultimate strength of the bar-plate connection in plate tension, bar shear and bar tension, as determined from static tests on bar-plate connection components [3, 4]. These tests showed that for plates having t $>8 \mathrm{~mm}$ the connection tensile strength (in the absence of bar shear) is governed by the strength of the bar material. The strength of the connection in bar shear is given by the following equation:

$H_{u B}=\left\{\begin{array}{l}210(t / 10)^{0.45} \mathrm{kN} \quad \text { for } t \leq 10 \mathrm{~mm} \text { and } d=25 \mathrm{~mm} \\ 210 \mathrm{kN} \text { for } t>10 \mathrm{~mm} \text { and } d=25 \mathrm{~mm}\end{array}\right.$ 
The tensile strength of the plate was assumed to be given by the uni-axial tensile strength of the steel plate material. The axial tensile forces in the bar connectors were calculated using the truss model, but factored by $\mathrm{s}_{\mathrm{x}} / \mathrm{h}_{\mathrm{c}}$ when $\mathrm{s}_{\mathrm{x}} / \mathrm{h}_{\mathrm{c}} \neq 1$ as suggested from static test measurements and finite element analysis [5]. Transverse shear resistance was calculated using the modified Eurocode2 [6] method as recommended in the Bi-Steel design guide.

Table 2. Ratio of Calculated to Measured Failure and Yield Loads and Midspan Deflections

\begin{tabular}{|c|c|c|c|c|c|c|c|c|c|c|c|}
\hline \multirow{2}{*}{ Beam } & \multicolumn{3}{|c|}{ Test measurements } & \multicolumn{6}{|c|}{ Prediction/Test } & \multicolumn{2}{|c|}{ Failure modes } \\
\hline & $\Delta_{0}$ & $\mathrm{P}_{0 \mathrm{P}}$ & $\mathrm{P}_{\mathrm{u}}$ & $\Delta_{0}$ & $\mathrm{P}_{0 \mathrm{P}}$ & $\mathrm{P}_{\mathrm{uP}}$ & $\mathrm{P}_{\mathrm{uBS}}$ & $\mathrm{P}_{\mathrm{uBT}}$ & $\mathrm{P}_{\mathrm{uVS}}$ & Predicted & Test \\
\hline BS1 & 2.6 & 1096 & 1591 & 1.06 & 1.11 & 1.01 & 1.20 & 1.34 & 0.62 & $\begin{array}{c}\text { Transverse } \\
\text { shear }\end{array}$ & Tension plate \\
\hline BS2 & 4.0 & 1738 & 1946 & 0.96 & 0.89 & 1.08 & 1.10 & 1.10 & 0.62 & $\begin{array}{c}\text { Transverse } \\
\text { shear }\end{array}$ & Tension plate \\
\hline BS3 & $>4.1$ & $>1984$ & $>1984$ & 0.92 & - & - & - & - & - & $\begin{array}{c}\text { Transverse } \\
\text { shear }\end{array}$ & No failure \\
\hline BS4 & 6.1 & 553 & 727 & 0.81 & 1.16 & 1.17 & 1.14 & 1.56 & 0.75 & $\begin{array}{c}\text { Transverse } \\
\text { shear } \mathrm{r}\end{array}$ & Tension plate \\
\hline BS5 & 7.9 & 786 & 873 & 0.79 & 1.04 & 1.28 & 1.06 & 1.30 & 0.74 & $\begin{array}{c}\text { Transverse } \\
\text { shear }\end{array}$ & Concrete shear \\
\hline BS6 & $>10.9$ & $>1110$ & 1110 & 1.17 & - & 1.62 & 0.93 & 1.02 & 0.80 & $\begin{array}{c}\text { Transverse } \\
\text { shear }\end{array}$ & Concrete shear \\
\hline BS7 & 7.1 & 333 & 545 & 1.08 & 1.30 & 1.05 & 0.96 & 1.39 & 0.84 & $\begin{array}{c}\text { Transverse } \\
\text { shear }\end{array}$ & Tension plate \\
\hline BS8 & 9.1 & 465 & 577 & 1.04 & 1.19 & 1.30 & 1.01 & 1.31 & 0.91 & $\begin{array}{c}\text { Transverse } \\
\text { shear }\end{array}$ & Bar shear \\
\hline BS9 & $>17.0$ & $>674$ & 674 & 1.21 & - & 1.80 & 0.95 & 1.12 & 1.02 & Bar shear & Bar shear \\
\hline BS10 & 8.9 & 245 & $\geq 415$ & 1.27 & 1.30 & 1.02 & 0.91 & 1.37 & 0.99 & Bar shear & Tension plate \\
\hline BS11 & 9.2 & 303 & 477 & 1.34 & 1.36 & 1.18 & 0.89 & 1.19 & 0.97 & Bar shear & $\begin{array}{c}\text { Bar/concrete } \\
\text { shear }\end{array}$ \\
\hline BS12 & $>20.0$ & $>501$ & 501 & 1.11 & - & 1.81 & 0.93 & 1.13 & 1.17 & Bar shear & $\begin{array}{c}\text { Bar/concrete } \\
\text { shear }\end{array}$ \\
\hline BS13 & 8.3 & 1201 & 1526 & 0.80 & 1.09 & 1.09 & 0.99 & 1.11 & 0.76 & $\begin{array}{c}\text { Transverse } \\
\text { shear }\end{array}$ & Tension plate \\
\hline BS14 & 13.2 & 1458 & 1583 & 0.56 & 1.04 & 1.27 & 0.97 & 1.08 & 0.83 & $\begin{array}{c}\text { Transverse } \\
\text { shear }\end{array}$ & Bar shear \\
\hline BS 15 & $>20.0$ & $>1047$ & 1047 & 0.95 & - & 1.37 & 0.94 & 1.08 & 0.84 & $\begin{array}{c}\text { Transverse } \\
\text { shear }\end{array}$ & $\begin{array}{c}\text { Bar } \\
\text { tension/shear }\end{array}$ \\
\hline BS16 & $>13.3$ & $>985$ & 985 & 0.99 & - & 1.80 & 1.01 & 1.16 & 1.01 & Bar shear & Bar tension \\
\hline BS17 & 13.2 & 758 & 851 & 0.84 & 1.13 & 1.29 & 1.11 & 1.33 & 1.05 & $\begin{array}{c}\text { Transverse/bar } \\
\text { Shear } \\
\end{array}$ & $\begin{array}{c}\text { Bar/concrete } \\
\text { shear }\end{array}$ \\
\hline BS18 & $>15.3$ & $->805$ & 805 & 1.06 & - & 1.68 & 1.18 & 1.41 & 1.25 & bar shear & $\begin{array}{c}\text { Concrete shear } \\
\text { bar tension }\end{array}$ \\
\hline
\end{tabular}

Note: Predicted transverse shear failure may result in either concrete shear or bar tension failure modes 
In Table 2, the ratios of the calculated to measured failure and yield loads are listed together with ratios of the calculated to measured (Eq. 5) midspan deflection at yield (where available) or at $2 / 3 \mathrm{P}_{\mathrm{u}}$. The predicted failure modes are also listed in Table 2. The mode for BS17 was taken as combined because the calculated failure load for bar shear was not more than $5 \%$ greater than that for transverse shear. Where a transverse shear failure is predicted, this may imply either a concrete shear failure mode or a bar tension failure mode.

According to the estimated maximum load for each possible failure mode, as listed in Table 2, the anticipated beam failure load is below the actual failure load. It can be seen in Table 2 that for the beams that developed tension plate failure in the tests, the measured tension plate yield load $\mathrm{P}_{0 \mathrm{p}}$ is generally below the predicted value, the ratio of prediction to test values ranging from 0.89 to 1.30 , and the predicted maximum load to cause tension plate failure is 1.01 1.17 times the actual load. This observation shows that the proposed method can overestimate the tension plate failure strength, mainly because the estimated plate forces were obtained by assuming the steel and the concrete to be linear elastic up to ultimate strength.

For the beams that developed bar shear failure in the tests, the predicted maximum load varies from 0.89 to 1.11 of the measured value. For beams BS15 and BS16, which had a bar tension failure, the calculated failure load for bar tension failure is respectively $108 \%$ and $116 \%$ of the measured maximum load. The ratio of the predicted transverse shear capacity to the measured value varies from beam to beam; for beam BS1 the estimated load to cause transverse shear failure is about $62 \%$ of the measured failure load to cause tension plate failure.

\subsection{Deflection}

Deflection has three quantifiable components - bending, slip, and transverse shear strain, that is:

$\Delta=\Delta_{B}+\Delta_{S L}+\Delta_{S H}$

The bending deflection for a beam with a central point load can be calculated by Eq. 6 :

$\Delta_{B}=\frac{P L^{3}}{48 E I_{e q}}$

where $I_{\text {eq }}$ is the second moment of area of the equivalent beam section as shown in Figure 2(b). The equation for slip deflection is developed from Wright and Oduyemi's model [7] assuming zero slip at the top plate. The approach proposed takes account of the bending deflection component of the beam and the additional deflection component due to interface slip between the steel plates and the concrete. It was observed in the beam tests that the slip at the top plate interface was nearly zero. Therefore, by introducing a further assumption of no top plate slip in the Wright \& Oduyemi model, a new equation was derived for the calculation of the midspan deflection due to interface slip only. The slip deflection for a simply supported beam loaded at midspan can be estimated by:

$\Delta_{S L}=\left(z_{b}-\frac{\left(C \cdot D \cdot z_{b}-1\right) z_{t}}{D}\right) H_{b} / q^{2} \Sigma E I$

where 


$$
\begin{aligned}
& C=\left[\frac{E_{c} A_{c u}\left(t_{t}+t_{c u}\right)}{2 \Sigma E I}\right] /\left[1+\frac{E_{c} A_{c u}}{E_{t} A_{t}}+\frac{E_{c} A_{c u}\left(t_{t}+t_{c u}\right) z_{t}}{2 \Sigma E I}\right], \quad D=1+\frac{E_{c} A_{c u}}{E_{t} A_{t}}+\frac{E_{c} A_{c u}\left(t_{t}+t_{c u}\right) z_{t}}{2 \Sigma E I} \\
& q=\sqrt{b_{1}+\frac{b_{2}}{D}\left(C D z_{b}-1\right)}, \quad H_{b}=C_{1} e^{q x}+C_{2} e^{-q x}+\beta L / 2 \\
& C_{1}=-C_{2}=-2 \beta e^{\frac{q L}{2}} / q\left(2+e^{q L}-\left(\frac{1-e^{q L}}{1-e^{-q L}}\right)\right), \quad \beta=\frac{\left(b_{o}+C b_{2}\right) P}{2 q^{2}} \\
& b_{1}=k_{b}\left[\frac{1}{E_{b} A_{b}}+\frac{1}{E_{c} A_{c u}}+\frac{z_{b}^{2}}{\Sigma E I}\right], \quad b_{2}=k_{b}\left[\frac{1}{E_{c} A_{c u}}-\frac{z_{t} z_{b}}{\Sigma E I}\right], \quad b_{0}=k_{b} \frac{z_{b}}{\Sigma E I}, \quad k_{b}=\frac{n_{b} K_{s, b}}{s_{x, b}}
\end{aligned}
$$

The slip stiffness given by Eq. 8 is based on the linear part of the load/slip curve for embedded bar-plate connections in shear [4].

$$
K_{s}=3.2 t+75 \quad \mathrm{kN} / \mathrm{mm} \quad \text { for } d=25 \mathrm{~mm}
$$

The shear deflection may be approximated by Eq. 9:

$$
\Delta_{S H}=\frac{P L}{4 G A_{c}}=\frac{\left(1+v_{c}\right)}{2 E_{c} B h_{c}} P L
$$

where $\mathrm{G}$ is the shear modulus $\mathrm{G}=\mathrm{E}_{\mathrm{c}} / 2\left(1+v_{\mathrm{c}}\right)$, and Poisson's ratio $v_{\mathrm{c}}=0.15$ is assumed for the concrete. $\mathrm{A}_{\mathrm{c}}$ is the cross-sectional area of concrete, which may be taken as. the total area $\mathrm{Bh}_{\mathrm{c}}$, which is assumed to include the effects of diagonal cracking. Table 2 compares calculated and experimental values of midspan deflection at tension plate yield, or $2 / 3 \mathrm{P}_{\mathrm{u}}$, as applicable.

\section{FATIGUE BEAM TESTS}

\subsection{Test Arrangement}

For each beam tested statically, a nominally identical beam was made to be tested in fatigue. The test arrangement and beam dimensions are shown in Figure 3 and Table 1. The cyclic load was provided by an Amsler pulsator operating at 4Hz, 24 hours per day. Prior to the fatigue test, each beam was loaded statically to the maximum fatigue load in three cycles. This enabled accurate measurements of the stresses and displacements, as well as a direct comparison with the measurements taken in the static tests.

\subsection{Test Results}

The calculated stress range was obtained from the truss model and neglecting friction between the steel plates and concrete. The plate tension is given at mid-span, where the highest stress range occurs, the bar shear is assumed to be nominally equal between bars, and the bar tension is also assumed to be nominally equal between bars according to the truss model and neglecting any effects arising from $\mathrm{s}_{\mathrm{X}} / \mathrm{h}_{\mathrm{c}} \neq 1$. Table 3 summarizes the test results. 


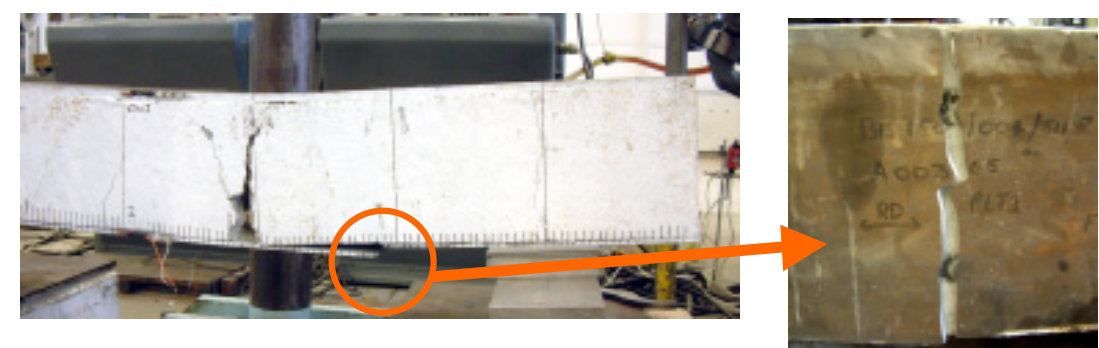

(a) Tension Plate Failure Mode (BF4)

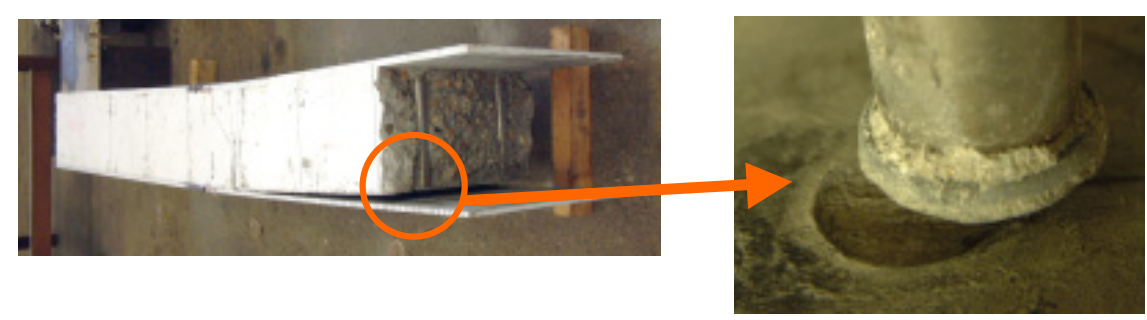

(b) Bar Shear Failure Mode (BF5)

Figure 5. Fatigue Failure Modes for the Tested Beams

Table 3. Beam Fatigue Test Results

\begin{tabular}{|c|c|c|c|c|c|c|c|}
\hline \multirow{2}{*}{$\begin{array}{c}\text { Test } \\
\text { No. }\end{array}$} & Beam ID & $\begin{array}{c}\mathrm{P}_{\min } \sim \\
\mathrm{P}_{\max } \\
\text { (tonne) }\end{array}$ & $\Delta \mathrm{P}(\mathrm{kN})$ & \multicolumn{2}{|c|}{$\begin{array}{c}\text { MCalculated Stress } \\
\text { Ranges }\left(\begin{array}{c}\mathrm{N}_{\mathrm{f}} \\
\text { (cycles) }\end{array}\right.\end{array}$} & Failure Mode \\
\hline B1 & $6 / 400 / 200 / 6$ & $7 \sim 70$ & 618.0 & 181.8 & 164.4 & 108,700 & Plate fracture \\
\hline B2 & $8 / 400 / 200 / 6$ & $6 \sim 60$ & 529.7 & 122.6 & 140.0 & 514,500 & Plate fracture \\
\hline B3 & $12 / 400 / 200 / 6$ & $10 \sim 100$ & 882.9 & 141.9 & 230.4 & 279,900 & Plate fracture \\
\hline B4 & $6 / 200 / 200 / 6$ & $4.5 \sim 45$ & 397.3 & 227.8 & 197.7 & 47,400 & Plate fracture \\
\hline B5 & $8 / 200 / 200 / 6$ & $4.5 \sim 45$ & 397.3 & 176.0 & 198.2 & 29,400 & Bar shear \\
\hline B6 & $12 / 200 / 200 / 6$ & $3.5 \sim 35$ & 309.0 & 94.1 & 154.8 & 442,000 & Bar shear \\
\hline B7 & $6 / 200 / 300 / 6$ & $1 \sim 10$ & 88.3 & 76.0 & 65.9 & 818,400 & Plate fracture \\
\hline B8 & $8 / 200 / 300 / 6$ & $1.5 \sim 15$ & 132.4 & 88.4 & 99.1 & 742,100 & Plate fracture \\
\hline B9 & $12 / 200 / 300 / 6$ & $2 \sim 20$ & 176.6 & 81.2 & 132.6 & 693,200 & Plate fracture \\
\hline B10 & $6 / 200 / 400 / 6$ & $2 \sim 11$ & 88.3 & 101.1 & 87.9 & 294,500 & Plate fracture \\
\hline B11 & $8 / 200 / 400 / 6$ & $2 \sim 11$ & 88.3 & 78.2 & 88.1 & 429,700 & Plate fracture \\
\hline B12 & $12 / 200 / 400 / 6$ & $2 \sim 11$ & 88.3 & 54.7 & 88.4 & $1,704,100$ & Plate fracture \\
\hline B13 & $10 / 300 / 200 / 8$ & $2 \sim 20$ & 176.6 & 44.1 & 45.8 & $2,945,200$ & Plate fracture \\
\hline B14 & $12 / 300 / 200 / 8$ & $3 \sim 30$ & 264.9 & 56.5 & 68.2 & $1,102,700$ & Plate fracture \\
\hline B15 & $10 / 300 / 300 / 6$ & $4.5 \sim 45$ & 397.3 & 148.0 & 206.2 & 109,200 & Plate fracture \\
\hline B16 & $12 / 300 / 300 / 6$ & $4.5 \sim 45$ & 397.3 & 125.8 & 203.9 & 29,700 & Bar shear \\
\hline B17* & $10 / 300 / 300 / 8$ & $2 \sim 16$ & 137.3 & 52.6 & 53.4 & $7,426,400$ & Plate fracture \\
\hline B18 & $12 / 300 / 300 / 8$ & $1.5 \sim 15$ & 132.4 & 43.1 & 51.1 & $2,404,500$ & Plate fracture \\
\hline
\end{tabular}

*Notes: (1) Ten preloading cycles of 1.5 45 tonnes were manually applied to beam BS17 before the pulsating load 2 16 tonnes was applied. 
Fatigue failure modes are illustrated in Figure 5. The bar forces cause local plate tension and bending, which adds to the effect of global plate tension. Fatigue loading caused local plate cracking which was initiated at a bar position and propagated across the plate. Bar failure without plate fracture occurred in three beams. In no case did the fracture occur at mid-span, which indicates that failure occurs where there is a combination of stress effects.

It is observed in Table 3 that for high load ranges and hence small fatigue life, bar shear fracture is the dominant mode of failure, and for smaller load ranges, the mode of failure is plate tension fracture. For high load ranges, local concrete crushing occurs and the bar bending stress increases, reducing the fatigue life of the connection in bar shear. For smaller stress ranges, the bar is better gripped by concrete and fatigue cracks propagate in the plate leading to plate fracture.

\subsection{Fatigue Life Calculation Method}

The current design guide method [2] assumes that the beam life is given by the smaller of the plate tension life and the bar shear life, determined from the BS 5400 [8] F and S curves respectively, assuming that each effect acts independently. Interaction between forces is not taken into account. Fatigue tests [5] on the bar plate connection in plate tension, bar shear and bar tension gave three $\mathrm{S}-\mathrm{N}$ curves for the fatigue life of the connection, given by the following equations:

$$
\begin{aligned}
& N_{f} \cdot \Delta \sigma_{P}^{3.5}=2.787 \times 10^{13} \cdot 0.657^{\alpha}, \quad \alpha=0 \text { and } 2 \\
& N_{f} \cdot \Delta \tau_{B}^{7.5}=2.767 \times 10^{21} \cdot 0.465^{\alpha} \quad, \quad \alpha=0 \text { and } 2 \\
& N_{f} \cdot \Delta \sigma_{B}^{5.2}=9.01 \times 10^{16} \cdot 0.638^{\alpha} \quad, \quad \alpha=0 \text { and } 2
\end{aligned}
$$

The plate tension fatigue curve is very close to the BS5400 F curve, however the bar shear curve lies below the BS5400 S-curve. This is due to concrete crushing around the connector, reducing the grip on the connector,introducing bending and therefore reducing the fatigue life. The predicted beam fatigue life is plotted in Figure $6 \mathrm{a}$, in relation to the calculated lives according to the design guide method. The plotted points are numbered, so the beams can be identified. The fatigue life by this method is non-conservative because the BS5400 S-type curve is non-conservative for embedded connections in shear and also because the bar tension component is ignored.

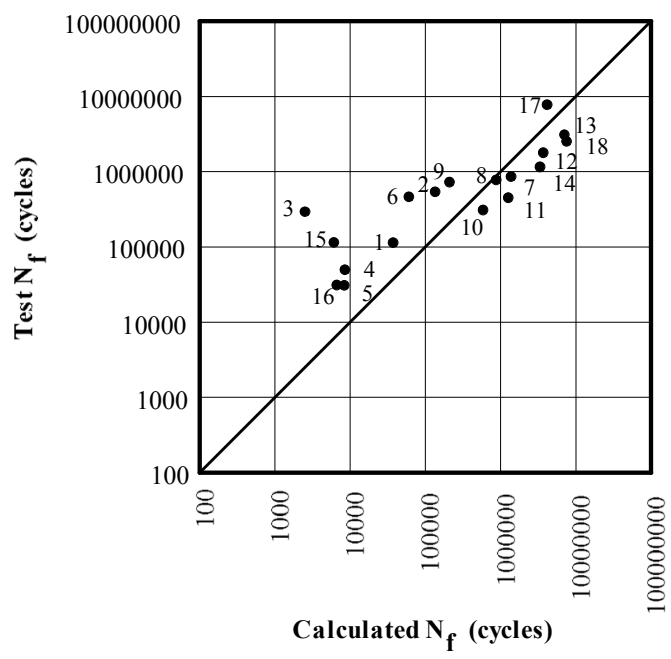

(a)

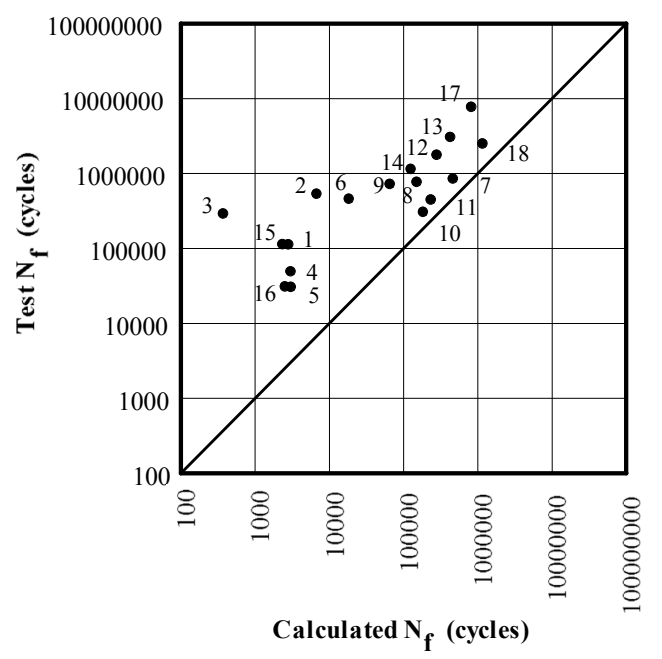

(b)

Figure 6. Comparison of Calculated to Predicted Beam Design Fatigue Life Using

(a) the Design Guide Calculation and (b) Proposed Method 
A method for calculating the interaction of load components at a connection is proposed, suggested by the Miner equation, which is used to estimate the cumulative effect of a load spectrum. The stress distribution within the connection will be different for each load component, but the damage caused by each component will reduce the lives of the other components compared to their lives if acting alone. That is, the force components interact. The suggested adaptation is as follows:

$$
\frac{N}{N_{\sigma P}}+\frac{N}{N_{\sigma B}}+\frac{N}{N_{\tau B}}=1
$$

where $\mathrm{N}$ is the number of cycles to cause failure of the connection, $\mathrm{N}_{\sigma \mathrm{P}}$ is the number of cycles to cause tensile failure of the plate with attached bars, according to Eq. 10; $\mathrm{N}_{\sigma \mathrm{B}}$ is the number of cycles to cause failure at the connection, resulting from bar tension, according to Eq. $12 ; \mathrm{N}_{\tau \mathrm{B}}$ is the number of cycles to cause failure at the connection, resulting from bar shear, according to Eq. 11. It was found that Eq. 13 can give non conservative estimates of life when the calculated life $\mathrm{N}_{\mathrm{f} \text {, calc }}$ exceeds $10^{5}$. A correction equation is therefore proposed for $\mathrm{N}_{\mathrm{f}, \text { calc }}>10^{5}$.

$$
N_{f, \text { calc }}^{\prime}=N_{f, \text { calc }}-\left(N_{f, \text { calc }}-10^{5}\right) \tan \theta \quad \text { for } N_{f, \text { calc }}>10^{5}
$$

$\theta$ rotates the data about $10^{5}$, and $\theta=40^{\circ}$ has been found to give satisfactory life estimates, as can be seen in Figure $6 b$.

\section{CONCLUSIONS}

The truss model gives conservative predictions of the beam failure loads. For ductile failure, beams should be designed to fail by yielding of the tension plate. For serviceability, it is tentatively suggested that beams should be designed so that the calculated load to cause plate yield is less than $2 / 3$ of the calculated load to cause any other mode of failure. A rational estimate of the beam deflection should take account of the influences of bending, slip, and shear deformation. It is recommended that for a Bi-Steel beam subjected to a central point load, deflection can be calculated in accordance with Eqs. 5-9. The fatigue lives of 18 beams were compared with the lives predicted by Eq. 13, which was found to over estimate life for lives greater than 100,000 cycles. This trend is corrected by Eq. 14.

\section{ACKNOWLEDGMENT}

The work reported here was sponsored by the Engineering and Physical Sciences Research Council (EPSRC) and by Corus. The authors would like to thank Mr Hugh Bowerman (Corus) for his technical support. 


\section{REFERENCES}

[1] Bowerman, H., Coyle, N. and Chapman, J.C., "An Innovative Steel/concrete Construction System”, The Structural Engineer, 2002, Vol. 80, No. 20, pp. 33-38.

[2] Bowerman, H.G, Gough, M.S. and King, C.M., "Bi-Steel Design and Construction Guide", British Steel Ltd, Scunthorpe, London, 1999.

[3] Xie, M. and Chapman, J.C., "Static and Fatigue Tensile Strength of Friction-welded Bar-plate Connections Embedded in Concrete", Journal of Constructional Steel Research, 2005, Vol. 61, pp. 651-673.

[4] Xie, M., Foundoukos, N. and Chapman, J.C., "Experimental and Numerical Investigation on the Shear Behaviour of Friction-welded Bar-plate Connections Embedded in Concrete", Journal of Constructional Steel Research, 2005, Vol. 61, pp. 625-649.

[5] Foundoukos, N., "Behaviour and Design of Steel-Concrete-Steel Sandwich Construction", Ph.D Thesis, Dept. of Civil and Environmental Engineering, Imperial College, London, 2005.

[6] European Committee for Standardization, Design of Concrete Structures, Eurocode 2, Brussels, 1992.

[7] Wright, H.D. and Oduyemi, T.O.S., "Partial Interaction Analysis of Double Skin Composite Beams", Journal of Constructional Steel Research, 1991, Vol. 19, pp. 257-279.

[8] British Standard Institution, Steel Concrete and Composite Bridges, BS5400 Pt 10, Code of Practice for Fatigue. BSI, London 1980.

\section{NOTATION}

A cross-sectional area

B width of plate

d bar diameter $(\mathrm{d}=25 \mathrm{~mm})$

E elastic modulus

f material strength

F member force

$\mathrm{h} \quad$ depth of truss (Figure 3)

$\mathrm{h}_{\mathrm{c}} \quad$ depth of concrete

$\mathrm{H} \quad$ horizontal shear force per bar

I $\quad 2^{\text {nd }}$ moment of area

$\mathrm{K}_{\mathrm{s}} \quad$ shear stiffness of bar connector

$\mathrm{L} \quad$ length of beam between supports

$\mathrm{m}$ modular ratio between steel and concrete

$\mathrm{N}_{\mathrm{f}} \quad$ number of cycles to failure

$\mathrm{P} \quad$ load applied at midspan of beam

$\mathrm{S}_{\mathrm{x}} \quad$ longitudinal spacing of bar connectors

$\mathrm{s}_{\mathrm{y}} \quad$ transverse spacing of bar connectors $\left(\mathrm{s}_{\mathrm{y}}=200 \mathrm{~mm}\right)$

$\mathrm{t} \quad$ plate thickness

$\mathrm{y}_{\mathrm{m}} \quad$ distance from neutral axis to the top of compression plate

$\mathrm{z} \quad$ distance from neutral axis

$\Delta \sigma, \Delta \tau \quad$ stress range

$\Delta \quad$ midspan deflection of beam

$\sigma, \tau \quad$ stress

\begin{tabular}{ll}
\multicolumn{2}{l}{ Common subscripts } \\
B & Bar \\
BS & bar shear \\
BT & bar tension \\
b & bottom plate \\
c & concrete \\
cu & un-cracked concrete \\
P & plate \\
t & top plate \\
u & ultimate load \\
VS & vertical shear \\
y & yield load
\end{tabular}

